DOI 10.37882/2500-3682.2021.04.10

\title{
КОНЦЕПТУАЛИЗАЦИЯ ЗАРУБЕЖНОГО ИССЛЕДОВАТЕЛЬСКОГО ДИСКУРСА О ПРОБЛЕМАХ СОЦИАЛЬНОЙ БЕЗОПАСНОСТИ В РОССИЙСКО-КИТАЙСКОМ ПРИГРАНИЧЬЕ
}

\section{CONCEPTUALIZATION OF THE FOREIGN RESEARCH DISCOURSE ON THE PROBLEMS OF SOCIAL SECURITY IN THE RUSSIAN-CHINESE BORDER AREA}

S. Kononov

Summary: The aim of the study is to conceptualize the discourse of Western studies devoted to the aspects of social security of the RussianChinese border area. The objectives of the study are to identify aspects of social security in Western descriptions of the Russian-Chinese borderlands in the XVII-XIX centuries; to determine the degree of influence of political conjuncture on the interpretation of the social security of the RussianChinese borderlands; to analyze modern transformations of the critical concept of social development of the Russian-Chinese border areas in the XXI century. The novelty of the study is determined by the fact that it is the first to conceptualize the assessments of factors and patterns of the formation of social security on the territory of the Russian-Chinese border in the works of European and American authors. The methodology of the research suggests the need to use the methods of critical analysis, comparative-historical and hermeneutical methods, systematization, but it is impossible without a certain reduction, abstraction and modeling. The result is to determine the vector of formation of the methodology of Western studies of the social security of the Russian-Chinese border area from early idealizations to positivist descriptions and the «critical concept», where Russia was assigned the role of a social threat. The second result is the identification of the content of the critical concept of social security of the Russian-Chinese border area, which consists in the fact that Russian-Chinese relations are perceived by Western researchers as a factor of lagging behind the development of regional society from the global level. The third result is an analysis of the transformation of the critical concept of social security of the Russian-Chinese border area, which consists in recognizing the independence of this regional space and its dependence not so much on Western trends in globalism, but on the influence of East Asian players, among which China is the leading one.

Keywords: social security, China, Russia, Russian-Chinese border area, Western studies of Russian-Chinese interaction, critical concept of social security of the Russian-Chinese border area.

\section{Введение}

\section{Актуальность}

роблема социальной безопасности приграничных регионов России и Китая представляет актуальную тему исследований российской, а также зарубеж-
Кононов Сергей Викторович

К.ф.н., старший преподаватель, Дальневосточное высшее общевойсковое командное училище имени Маршала Советского Союза К.К. Рокоссовского kononov7744@yandex.ru

Аннотация: Целью исследования проведение концептуализации дискурса западных исследований, посвященных аспектам социальной безопасности российско-китайского приграничья. Задачами исследования является выделение аспектов социальной безопасности в западных описаниях российско-китайского приграничья в XVII-XIX вB.; определение степени влияния политической конъюнктуры на интерпретации социальной безопасности российско-китайского приграничья; анализ современных трансформаций критической концепции социального развития приграничных российско-китайских территорий в XXI в. Новизна исследования определяется тем, что в нем впервые проводится концептуализация оценок факторов и закономерностей становления социальной безопасности на территории российско-китайского приграничья в трудах европейских и американских авторов. Методология исследования предполагает необходимость привлечения методов критического анализа, сравнительно-исторического и герменевтического метода, систематизации, однако невозможно без определенной редукции, абстрагирования и моделирования. Результатом является определение вектора формирования методологии западных исследований социальной безопасности российско-китайского приграничья от ранних идеализаций до позитивистских описаний и «критической концепции», где России отводилась роль социальной угрозы. Вторым результатом является выявление содержания критической концепции социальной безопасности российско-китайского приграничья, которое заключается в том, что российско-китайские отношения воспринимаются западными исследователями, как фактор отставания развития регионального общества от общемирового уровня. Третьим результатом является анализ трансформации критической концепции социальной безопасности российско-китайского приграничья, которая заключается в признании самостоятельности этого регионального пространства и зависимости его не столько от западных трендов глобалистики, сколько от влияния восточно-азиатских игроков, ведущим среди которых является Китай.

Ключевые слова: социальная безопасность, Китай, Россия, российско-китайское приграничье, западные исследования российско-китайского взаимодействия, критическая концепция социальной безопасности российско-китайского приграничья.

ной англоязычной и китайской историографии. Общий контекст этих произведений посвящается анализу процессов взаимодействия Китая и России, и затрагивает различные аспекты влияния этих государств на окружающие социальные пространства. Среди этих направлений значимое место занимает зарубежная историография, в рамках которой были составлены наиболее 
ранние описания Китая и окружающих его социальных пространств. Несмотря на то, что в рамках этих исследований на Западе социальная безопасность российско-китайского приграничья не составила специального предмета исследования, различные ее аспекты представлены в публикациях, посвященных теме российскокитайского взаимодействия, а также взаимодействия западных стран и Китая. При этом, в отличие от российских и китайских авторов, находящихся в рамках этого процесса, западные исследователи предлагают свои подходы, методы и мировоззренческую оценку, отличием которой является взгляд извне, с учетом западной научной методологии, а также теорий, представлений и ценностей. Это обусловило наличие специфических для западного мировосприятия характеристик российскокитайского взаимодействия, а также оценок влияния этих стран на окружающее социальное пространство. Теоретическое значение исследования связывается с определением специфики западных подходов к анализу и описанию факторов социальной безопасности российско-китайского приграничья, а также обнаружении противоречия между данной концепцией и признаваемой канонической концепцией региональной безопасности А. Ачарья [8], Б. Бузана [12], Л. Фоусета [15], Дж. Ньюмана [25], синтезировавших представления конструктивизма и социального реализма. Практическое значение исследования определяется возможностью выделения описательных и оценочных категорий в западных концепциях социальной безопасности российско-китайского приграничья, и определить степень их применимости при исследовании и анализе проблем развития данной социальной системы.

\section{Степень исследованности}

Элементы социальной безопасности представлены в исследованиях российско-китайского приграничья Х.Б. Морзе [3], Д. Даллина [13], А. Форсайта [14], Р. Квестида [21], Ван дер Ойе [28], С. Коткина [20], В. Гарнета [17]. Большое влияние на формирование представлений о данном предмете оказали публикации политических деятелей, таких как 3. Бжезинский [2], Г. Киссинджер [19], М. Тэтчер [5], М. Олбрайт [4], а также представителей современного экспертного сообщества в области регионалистики, таких как С. Бланк [12], М. Харрисон [7], Ло Б [22], М. Фрейре [16], С. Арис [11], Т. Гомар [18], Дж. Розман [27], Е. Вишник [29], Т. Пемпель [26], М. Алагаппа [9], А. Масафуми [23].

\section{Результаты:}

1. Социальная безопасность российско-китайского приграничья не является особым предметом исследования западной историографии, однако ее аспекты представлены в публикациях, посвященных теме российско-китайского взаимодействия. Западные исследователи, в отличие от российских и китайских авторов, находящихся в рамках этого процесса, предлагают подходы и мировоззренческую оценку, спецификой которой является взгляд извне, а также опора на западную методологию, теории и ценности, которые повлияли на трансформации понимания ими социальной безопасности в российско-китайском приграничье. В частности, на протяжении XVII-XIX вв. отношение европейских исследователей к влиянию Китая на окружающее приграничье определяла идеализация Китая, как государства олицетворявшего совершенное общественное устройство. В конце XIX - нач. XX в. благодаря распространению позитивизма, идеализированный образ влияния Китая на социальную безопасность прилегающих территорий, сменился на представления, рождаемые исследованиями, основой которых был эмпирический материал, касающийся политического, экономического и социального взаимодействия В российско-китайском приграничье. C сер. XX в. развитие западного понимания проблемы социальной безопасности в российско-китайском приграничье оказалось зависимым от политической конъюнктуры, которая стала определять описание российско-китайских отношений, понимаемых теперь главным образом, в контексте идеологии противостояния цивилизаций Востока и Запада.

2. Содержание критической концепции социального развития приграничных российско-китайских территорий заключается в том, что российскокитайские отношения воспринимаются западными исследователями, как важнейший фактор социального развития приграничных регионов, который объявляется причиной отставания развития регионального общества от общемирового уровня. Эта концепция основана на положении о том, социальные проблемы российско-китайского приграничья не имеют самостоятельного характера, так как полностью производны от российско-китайского политического, военного, экономического и социального противостояния. Согласно этой концепции, Россия является слабым агрессором на колонизованных землях, расположенных в регионах китайского приграничья, которые удерживаются только с помощью военной силы, однако не развиваются и не используются.

3. Современная концепция западных авторов в отношении проблем региона российско-китайского приграничья трансформируется в сторону признания самостоятельности этого регионального пространства, и зависимости его не столько от западных трендов глобалистики, сколько от влияния восточно-азиатских игроков, ведущим среди которых является Китай. Трансформации «критической концепции» в исследованиях социальной безопасности российско-китайского приграни- 
чья, определяются убеждением в необходимости организации сотрудничества между Китаем и США, партнерские усилия которых могут стать основой для разрешения социальных проблем региона, ведущей из которых представляется присутствие ослабевшей России. С точки зрения западных экспертов, отсталость социального развития региона российско-китайского приграничья обусловлена нежеланием менять нормативные устои социальной жизнедеятельности российского и китайского сообществ, основанные на принципах коммунитаризма, на либеральные порядки, определяющие порядок жизнедеятельности западных обществ. В то же время западные исследователи российско-китайского приграничья, практически не используют наработки теории региональной безопасности, так как, следуя политической конъюнктуре, практически не обращают внимания на реальные процессы социальных трансформаций, затрагивающие региональный социум, благодаря региональному взаимодействию, а также самостоятельному развитию в политической, экономической, социальной сферах.

\section{Обсужкение результатов}

\section{Аспекты социальной безопасности в западных описаниях российско-китайского приграничья в XVII-XIX вв.}

Обсуждение данной темы сопровождало практически всю историю формирования западных исследований Китая и окружающих его территорий, в течение которой концептуальные оценки влияния этой страны на окружающие социальные пространства претерпевало существенные трансформации. Одной из первых оценок состояния социальной безопасности территорий, сегодня входящих в регион российско-китайского приграничья, можно считать описания европейских путешественников, таких как М. Поло, Дж. Мандевиль, содержащих первый опыт осмысления влияния Китая на окружающие социальные пространства. Как пишет О. Фишман, именно путешественники, торговцы и миссионеры заложили основу западного восприятия Китая и всего, что связано с его влиянием в западном обществе [6]. По мнению этого автора, рассмотрение проблематики китайского влияния на социальные устои взаимодействующих с этой страной обществ у европейцев проходило в рамках концепции «культурной адаптации», которая предполагала принятие идеализированного образа Китая, как сказочной страны, олицетворявшей совершенное общественное устройство.

В конце XIX - нач. XX в. благодаря распространению методологии, основанной на принципах позитивизма, идеализированный образ, связанный с верой благотвор- ное влияние Китая на социальную безопасность прилегающих территорий варварских государств, сменился на представления, рождаемые научными исследованиями, основой которых являлся эмпирический материал, избавленный от аналитических комментариев, и мировоззренческих оценок. Такие представления отражали содержание работ Г. Говена, М.П. Прайса, Г.Б. Морзе [3], которое определялось описанием фактологической стороны, касающейся российской и китайской политики на Дальнем Востоке, включающей описание политических и финансовых операций между странами, развития экономики в приграничных территориях, железнодорожного строительства, военных операциях на русско-японском фронте, боксерском восстании. Таким образом, основу научного подхода западных авторов к проблеме социальной безопасности российско-китайского приграничья на рубеже XIX-нач. XX в. составил позитивистский подход, отраженный в ряде исторических описаний процессов российско-китайского взаимодействия.

\section{Влияние политической конъюнктуры на интерпре- тации социальной безопасности российско-китай- ского приграничья в исследовательских концепциях западных авторов в ХХ в.}

C сер. XX в. развитие западного понимания проблемы социальной безопасности в российско-китайском приграничье оказалось зависимым от политической конъюнктуры, которая стала определять описание российско-китайских отношений, понимаемых теперь главным образом, в контексте идеологии противостояния цивилизаций Востока и Запада. От отстраненных от мировоззренческих оценок позитивистских исследований авторы публикаций, посвященных российско-китайскому взаимодействию, перешли к произведениям, содержащим концептуальный анализ, содержащий жёсткую критику российской политики в российско-китайском приграничье. В этом контексте социальная безопасность российско-китайского приграничья на Западе понималась только как проблема внешней политики, международных отношений и борьбы России и Китая за влияние в Восточноазиатском регионе.

В частности, это касается публикаций Г.Б. Морзе, который, изменив теоретическую базу своих работ, в начале 30-гг XX в. [24], выпустил новый вариант исследования о российско-китайском взаимодействии, где были дана негативная оценка российской политики на Дальнем Востоке. Проблемы русско-китайских отношений в этот период трактовались только через призму концепции российской экспансии, предполагающей оценку любых российских действий только как агрессии в отношении Китая и его населения, проживавшего в приграничных территориях. В течение 50-х гг. вышел целый ряд исследований, направленных на разоблачение политики России на Дальнем Востоке. Например, жесткая оценка 
российской политики была изложена в обличительной монографии Д. Даллина, посвященной событиям русскокитайской и русско-японской войны. Неоднозначным моментами истории взаимодействия между Россией и Китаем были посвящены работы П. Клайда, А. Улара, Р. Ли, Ч. Тана, которые обосновывали реальность «желтой опасности» для российского Дальнего Востока. Они писали о слабых позициях России на Дальнем Востоке, о китайской контрабанде, контрафактной деятельности, ходе военного противостояния между Китаем и Россией. В публикациях Дж. Стефана и Дж. Форсайта проанализированы противоречия в развитии Дальнего Востока, которые возникли в результате имперской политики России в Маньчжурии [14].

На рубеже 60-х гг. XX в. в связи с временным потеплением отношений между Советским Союзом и западными странами ознаменовались появлением аспектов признания позитивной роли России на Дальнем Востоке в работах А. Малоземова, Дж. Ленсена, Э. Клабба, которые анализируют противоречия между невысоким экономическим потенциалом и значительными политическим претензиями России на Дальнем Востоке. Однако делая общие выводы и уделяя внимание такой проблеме как «желтая опасность», которую ощутили западные страны в это время, они, в то же время писали о том, что Россия может стать силой, способной спасти Европу от угрозы «китайского нашествия». Эта же идея прослеживается в публикациях В. Коларза и Дж. Колмаса, где позитивно оценивалась внешне политика России на Тибете и в Маньчжурии. Однако в 70-80 е гг. XX в. в связи с обострением «холодной войны» оценки политики России на Восток со стороны западных исследователей вновь приобрели более жесткий и односторонний характер. В частности, дальневосточную политику Росси как тупик описывают Я. Ниш, Д. Макдональд, С. Пэйн, Р. Квестид [21], характеризующие внешнюю политику России как агрессию, нацеленную на аннексию китайских территорий.

\section{Современное развитие критической концепции сочиального развития приграничных российско-ки- maйских территорий}

В современной западной историографии продолжает уделяться внимание вопросам и проблемам российско-китайских отношений. При этом вывод, который напрашивается на основании содержания этих исследований, заключается в том, что российско-китайские отношения воспринимаются западными исследователями, как важнейший фактор социального развития приграничных регионов. Такие исследователи, как Ш.У. Гарнетт, П. Хопкирк, Д. Уинтл Д.С. ван дер Ойе[28] рассматривают проблематику российско-китайского взаимодействия исходя из концепции столкновения цивилизаций Востока и Запада, где Китай и Россия представляют разные аспекты цивилизации Востока, что и является причиной отставания развития общества в данном регионе. Схожих убеждений придерживается С.Г. Маркс и С. Коткин [20], развивающие концепцию попытки российской колонизации и освоения Северного Китая за счет железнодорожного строительства, в котором магистраль выступает в роли инструмента освоения территорий, а социальная инфраструктура представляется как следствие построения железной дороги. Авторы доказывают, что причиной возможной китайской агрессии в регионах российско-китайского приграничья являются социальные проблемы отдаленных территорий, такие как слабая заселенность, неразвитая инфраструктура, отсутствие сильного управления и военной защиты.

Вопросы российско-китайского противостояния, которым посвящены работы по исследованию приграничных с Китаем районов российской Сибири и Азии в их публикациях освещаются в рамках критической концепции, утверждающей реальность аннексии территорий Китая со стороны России. Эта концепция основана на положении о том, что Россия целенаправленно стремилась к установлению своих границ на Востоке, где как пишет Е. Олвоз, она проводила кампании по их расширению, однако усилий для их социального развития не прилагала. Поэтому, с точки зрения данной концепции, которую сегодня представляют С. Пэйн и Ш. Гаммет, социальные проблемы российско-китайского приграничья не имеют самостоятельного характера, так как производны от российско-китайского противостояния.

Таким образом, на Западе за последние десятилетия XX в. сформировалась критическая концепция социального развития приграничных российско-китайских территорий. Согласно этой концепции, Россия является слабым агрессором на колонизованных землях, которые удерживаются с помощью военной силы, но не развиваются и не используются. В силу этого формулируется принцип западных исследований социальной безопасности в российско-китайском приграничье, который заключается в утверждении о том, что изменения социальной структуры российского китайского приграничья, являются элементом действия обширной системы мирового порядка, который в современных условиях представляет «однополярный мир». В рамках этой концепции Россия представляет не реальную геополитическую силу, а угрозу, которая должна быть устранена с помощью сил «однополярного мира».

В начале XXI в. проблемы социальной безопасности российско-китайского приграничья стали одним из аспектов политических исследований 3. Бжезинского [2], Дж. Бланка [12], Г. Киссинджера [19], М. Тэтчер [5], М. Олбрайт [4], М. Харрисона [7]. Их публикации содержат много общих позиций, отражающих очевидный антироссийский контекст, заключенный в идее о том, что ведущим игроком, который формирует социальную си- 
туацию на территории приграничья между Россией и Китаем являются США. При этом в силу того, что власть этого государства над представленными территориями не является очевидной, США должны использовать имеющееся в регионе противостояние между Россией и Китаем для установления последующего контроля над ним. Данная ситуация по мнению западных авторов, является разрешимой, только с учетом того, что такой участник приграничного взаимодействия, как Китай, понимает необходимость обеспечения социальной безопасности и вносит свой посильный вклад в становление этой социальной системы. Поэтому, достижение этой цели возможно только в случае организации стратегического сотрудничества США с КНР.

Как подчёркивает 3.К. Бжезинский, мировое господство США позволяет Америке вступить в союз с Китаем на тех территориях, которые входят в обширную зону китайского влияния. Причиной этого, по мнению автора, является то, что представляющая угрозу региональному порядку Россия отличается слабостью по сравнению с намного превосходящим ее по экономической и демографической мощи Китаем. Как полагает автор, союз с Китаем, основанный на паритетном разделении сфер влияния, позволит США создать «большую двойку», способную совместно решать все, в том числе социальные проблемы территорий, прилегающих к Китаю. Схожую точку зрения выражает Г. Киссинджер, стремящийся к обоснованию концепции эффективного взаимодействия КНР и США. По мнению Г. Киссинджера, при проведении региональной политики США должны учитывать, что Китай является сюзереном Восточной Азии и Тихоокеанского региона, который контролирует прилегающие к его границам территории варварских вассальных государств. Безусловно, что само это развитие понимается, как движение в направлении вытеснения России из региона, так как Г. Киссинджер считает это условием формирования будущего проекта взаимодействия Китая и Америки в рамках решения социальных проблем этих территорий [19].

Большое внимание ведущей роли Китая в исследуемом регионе уделяется в публикации М. Тэтчер, которая считает, что китайские традиции управления и социальной жизни оказывают определяющее влияние на развитие окружающих Китай государств [5]. Однако это влияние, является очень неоднозначным и поэтому Китай требует к себе пристального внимания со стороны США, стремящихся к контролю над процессами, происходящими вокруг Китая. Китай, по ее мнению, также как и по мнению М. Олбрайт, является региональной силой, которую невозможно игнорировать, так как он чересчур велик и чересчур репрессивен. Америка и Европа, несмотря на нежелание поддаваться их влиянию со стороны Китая, должны искать пути сближения с этим государством, как с наиболее влиятельной силой, с которой возможно строить систему социальной безопасности в Восточной Азии [4].

Такие же положения доказываются экспертами, отмечающими, что в Китае воспринимают Россию только в качестве ресурса и подчиненной силы, используемой для проведения своей политической и экономической стратегии. В частности, С.Д. Бланк, анализируя усилия России в восточном направлении, доказывает их бесперспективность, показателем которой является череда неудач, подорвавших ее стремление к усилению организации социальной инфраструктуры в российскокитайском приграничье. Этот автор пишет, что Россия сознательно отдает инициативу в руки Китая и соглашается на подчиненное положение. Россия, согласно мнению данного исследователя, предоставляет китайским партнерам территории и сырьевые ресурсы в обмен на любые виды помощи и финансирования [12]. Идеи о том, что современное взаимодействия между Россией и Китаем нацелено на пользу Китаю, становящемуся новой глобальной силой, развиваются Б. Ло [22], М. Фрейре [16], С. Арисом [11], Т. Гомаром [18], Г. Розманом [27], Э. Вишник [29], которые пишут об оттеснении России на периферию регионального взаимодействия. Поэтому современная концепция западных авторов в отношении проблем региона российско-китайского приграничья трансформируется в сторону признания самостоятельности этого регионального пространства, и зависимости его не столько от трендов глобалистики, сколько от влияния восточно-азиатских игроков, ведущим среди которых является Китай [30]. В частности, эту проблему анализирует Т.Д. Пемпель, который считает, что к особенностям регионального Восточно-азиатского социального пространства необходимо относить доминирующее влияние государств на все виды социального взаимодействия. Этот автор доказывает, что страны Восточной Азии, по сравнению со странами Европейского континента демонстрируют нежелание развивать социальное взаимодействие на региональном уровне. Все решения в отношении судьбы и направленности развития социальных пространств, подконтрольных этим государств, принимаются только на уровне самих государств без согласования с кем-либо и даже без учета мнения тех, на какого они направляются [26].

Эта социальная стратегия региональных политиков, как представляется современным западным авторам, таким как М. Алагаппа [9], А. Масафуми [23], не является продуктивной, так как попытки организации региональных союзов, пытающиеся противопоставить себя общемировому порядку, выстроенному по принципу «однополярного мира», не имеют смысла, а только порождают атмосферу страха и недоверия. Эти авторы, развивают модифицированный вариант критической концепции регионального развития, в котором Россия, также как Китай и Япония, критикуются за попытку, основываясь на 
ограниченных в политических и экономических возможностях двусторонних альянсах, разрешить социальную ситуацию в районе российско-китайского приграничья, привели регион к состоянию масштабного кризиса, продолжавшегося на протяжении всего XX в.

Таким образом, содержание современных трудов зарубежных авторов, посвященное социальной безопасности российско-китайского приграничья, нацеливается конструирует ту картину социального развития и социальной безопасности, актуализация которой может мобилизовать общество на достижение идеалов, основанных на ценностях глобализма и либерализации общественной жизни. Очевидно, что такая методология носит инструменталистский характер, нацеленный конструирование нормативных и ценностных представлений общественных групп на территории региона. Таким образом, современные тенденции развития западной методологии исследований социальной безопасности в рамках российско-китайского приграничья направлены на обоснование такой модели социальной безопасности региона, в рамках которой он должен развиваться, подчиняясь общему процессу развития мировой цивилизации в рамках глобализационного процесса, направляющего региональное развитие на включение в свои ареалы. При этом обратная тенденция, представляющая процесс социального развития региона, основанный на региональных социальных ценностях, по отношению к российско-китайскому приграничью оценивается, как угроза социальному развитию. Это входит в противоречие с теоретическими положениями современного научного дискурса, которые доказываются А. Ачарья, Бузаном, Д. Лейком, Дж. Ньюманом [25], выступающими с требованиями, согласно которым состояние социальной безопасности регионов не может только конструироваться, так как оно имеет объективные параметры своей структуры и реальные проблемы и тенденции развития. Поэтому становится очевидным, что практическое значение для организации современных исследований социальной безопасности российско-китайского приграничья, должна иметь реализация модели исследований, разработанной В. Кое, К. Кузаком, Ц. Фоусетом [15]. В их трудах разрабатывается методология структурного реализма, учитывающего положения как инструменталистских и конструктивистских концепций, так и положения цивилизационного и системного подходов, в которых отражались актуальные проблемы современности и угрозы выживанию региональных сообществ. Эта модель настоятельно требует учета влияния, которое оказывает каждый регион, противопоставляющий внешнему воздействию свою систему интересов и ценностей, которая, обладает своим потенциалом, сформированным историческими, природногеографическими условиями, регулирующими отношения природы, человека, общества и мира, придающим ему единство и системность.

\section{Выводы:}

Западный научный дискурс, посвященный влиянию Китая на прилегающие территории России, несмотря на разнообразие многочисленных оценок, имеет общий теоретический контекст, посвященный выяснению сущности влияния Китая и России на окружающие социальные пространства. Исследование показало наличие специфики европейского и американского восприятия образов Китая и России, связанной со стремлением прояснить особенности российско-китайских отношений с учетом западных теорий, представлений и ценностей, влияние на которые оказывает политическая конъюнктура. В частности, такой особенностью является представление проблематики российско-китайского приграничья, как проблемы внешней политики, международных отношений и экспансии России и Китая в восточноазиатском регионе. Общей тенденцией развития западной историографии в отношении проблемы социального развития и безопасности регионов российско-китайского приграничья является разработка «критической теории», в рамках которой проводится обоснование невозможности социального развития региона российско-китайского приграничья в рамках только региональных, российских или китайских ценностей. Представители критической теории разрабатывают обоснование необходимости развития такого регионального порядка, который был бы ориентирован на социальные ориентиры, принимаемые мировым сообществом, под которыми имеются в виду ценности глобализма и либерализма. В то же время зарубежные исследователи понимают и констатируют, что в региональном пространстве взаимодействия между Россией и Китаем господствуют совсем другие ценности, не совместимые ни с политическими, ни с «духовными» ценностями западного общества. При этом, с точки зрения западных экспертов, именно приверженность традиционным порядкам, основанным на принципах коммунитаризма и нежелание менять эти нормативные устои на либеральные, является причиной отсталости социального развития региона российско-китайского приграничья, ведущей к угрозе политического, экономического, демографического поглощения со стороны более развитых соседей. Анализируя содержание специфических для региона «азиатских ценностей», они пришли к выводу о невысокой степени их развития, утверждая, что руководство России и Китая не желает вступать в процессы интеграции с мировым сообществом, предпочитая регионализм в качестве площадки для социального развития. Здесь важно, что внимание ими уделяется главным образом, сохранению неизменности идеологических устоев в то время, как практически не анализируются процессы социальных трансформаций, затрагивающие региональный социум, благодаря мировому и региональному взаимодействию, а также самостоятельному развитию в политической, экономиче- 
ской, социальной сферах. Проведенное исследование раскрывает необходимость применения результатов западных исследований российско-китайского приграничья в рамках методологии А. Ачарья, Б. Бузана, Д. Лейка, Дж. Ньюмана, Ц. Фоусета. В их трудах разрабатывается методология структурного реализма, учитывающего положения инструменталистских и конструктивистских концепций, и положения цивилизационного и системного подходов, в которых отражались актуаль- ные проблемы современности и угрозы выживанию региональных сообществ. Эта модель настоятельно требует учета влияния, которое оказывает каждый регион, противопоставляющий внешнему воздействию свою систему интересов и ценностей, которая, обладает своим потенциалом, сформированным историческими, природно-географическими условиями, регулирующими отношения природы, человека, общества и мира, придающим ему единство и системность.

\section{ЛИТЕРАТУРА}

1. Blank S. Towards a New Chinese Order in Asia: Russia's Failure // NBR Special Report, 2011. N. 26. Pp. 4-19.

2. Бжезинский 3. Великая шахматная доска: Господство Америки и его геостратегические императивы. М.: АСТ, 2013.703 с.

3. Морзе Х.Б. Международные отношения Китайской империи. Нью- Йорк: Изд-во Нью-Йорк, 1918. 1570 с.

4. Олбрайт М. Религия и мировая политика. М.: Альпина, 2007. 352 с.

5. Тэтчер М. Искусство управления государством: стратегии для меняющегося мира. М.: Альбина Паблишер, 2003. 504 с.

6. Фишман 0.Л. Китай в Европе: миф и реальность (XIII-XVIII вв.). СПб.: Петербургское востоковедение, 2003.544 с.

7. Харрисон М. «Спотыкающийся медведь, парящий дракон: мог ли Советский Союз пойти по китайскому пути? // Вестник Европы. 2014. № 38. [Электронный ресурс]. Режим доступа: http://magazines.russ.ru/vestnik/2014/39

8. Acharya A. The End of the American World Order. Cambridge: Polity. 2018. $224 \mathrm{p}$.

9. Alagappa M. International Peace in Asia: Will It Endure? // The ASAN Forum. 2014. [Электронный ресурс]. Режим доступа: http://www.theasanforum.org/ international-peace-in-asia-will-it-endure/

10. Allworth E. Central Asia, 120 Years of Russian Rule. Durham, N.C.: Duke University Press, 1989. 606 p.

11. Aris S., Snetkov A. Russia's Foreign Policy-Current Trajectory and Future Prospects // Russian Analytical Digest. 2018. No. 213, 7 February. Pp. 9-13.

12. Blank S. Towards a New Chinese Order in Asia: Russia's Failure // NBR Special Report, 2011. N. 26. Pp. 4-19.

13. Buzan B., Lawson G. The Global Transformation: History, Modernity, and the Making of International Relations. Cambridge University Press. 2015. Pp. 157- 182.

14. Forsyth J. A History of the Peoples of Seberia. Russia's North Asian colony 1581-1990. Cambridge: Cambridge univ. press, 1994. - XX, 455 C.

15. Fawcett L. Regionalism by Emulation: Considerations across Time and Space // Interregionalism and the European Union. Post-revisionist Approach to Europe's Place in a Changing World. Abington: Routledge, 2016. Pp. 33-55.

16. Freire M.R., \& Simão, L. The modernisation agenda in Russian foreign policy // European Politics and Society, 2015. 16(1). Pp. $126-141$.

17. Garnett Sh.W. The New Central Asia: In Search of Stability // A Report to the Trilateral Commission. 2000.80 p.

18. Gomart Th. Guerres invisibles - Nos prochains défis géopolitiques. Paris: Éditions Tallandier, 2021. 317 p.

19. Kissinger H. On China. New York: The Penguin Press, 2011. 586 p.

20. Kotkin S. Manchurian Railways and the Opening of China: An International History. Armonk; NY, 2010. 235 p.

21. Quested R.K.I. «Matey» imperialists. The Tsarist Russians in Manchuria 1895-1917. Hong-Kong: Centre of Asian Studies, 1982.430 pp.

22. Lo B. Russia and the New World Disorder. Washington: Brookings Institution Press. 2015. 344 p.

23. Masafumi A. The China-Russia-Japan Military Balance in Manchuria, 1906-1918 // Modern Asian Studies. 2010. Nov. Vol. 44. Iss. 6. P. 1283-1311

24. Morse H.B. MacNair H.F. Far Eastern international relations. Boston: Houghton Mifflin and Company. 1931. 846 p.

25. Nyman J. What is the value of security? Contextualising the negative/positive debate. Review of International Studies. 2016. 42 (5). Pp. 521-839.

26. Pempel T.J., Tsunekawa K. Two Crises, Different Outcomes: East Asia and Global Finance. By. Ithaca, NY: Cornell University Press, 2016. 280p.

27. 27. Rozman G. Chinese Views of Chinese-Russian Relations and the U.S. Pivot // Uneasy Triangle: China, Russia, and the United States in the New Global Order," Center on Global Interests. 2015. October. Pp. 19-26

28. Schimmelpenninck van der Oye D. Toward the Rising Sun: Russian Ideologies of Empire and the Path to War with Japan. DeKalb, III., 2001. 329 p.

29. Wishnick E. The New China-Russia-U.S. Triangle // NBR Analysis Brief. 2015. [Электронный ресурс]. Режим доступа: https://www.academia.edu/43545459/ The_New_China_Russia_U_S_Triangle

30. Zhukov A., Bernyikevich T. Religious security of the Russian Federation as Reflection object of the philosophy and religious studies // MATEC Web of Conferences. electronic edition. 2018. C. 10003.

() Кононов Сергей Викторович (kononov7744@yandex.ru).

Журнал «Современная наука: актуальные проблемы теории и практики» 